Supporting Information

\title{
Dispersion Forces and the Molecular Origin of Internal Friction in Protein
}

Pulikallu Sashi, Dasari Ramakrishna, and Abani K. Bhuyan*

School of Chemistry, University of Hyderabad, Hyderabad 500046, India

Correspondence: Abani K. Bhuyan

akbsc@uohyd.ac.in

\section{Methods}

NMR Spectroscopy and Calculation of Ring-Flip Rate Constant. Sample solutions containing $2 \mathrm{mM}$ cytochrome $c$ and different w/v percent glycerol were prepared in $50 \mathrm{mM}$ phosphate, $\mathrm{pH}$ 7. For each sample, exchange spectra (EXSY) with mixing times $\left(\tau_{m}\right) 3.75$, $18.8,37.5,75,112.5$, and $150 \mathrm{~ms}$ were recorded in a $500 \mathrm{MHz}$ Bruker spectrometer using the basic pulse sequence described earlier. ${ }^{1,2}$ No attempt was made to suppress glycerol resonances. Spectra were run at several concentrations of glycerol as high as $50 \%$, but higher glycerol content introduces difficulty in analysis. Figure S1 illustrates the relevant region of spectra at indicated $\%$ glycerol content recorded with $\tau_{m}=37.5 \mathrm{~ms}$. Spectra were processed and analyzed using TopSpin. 


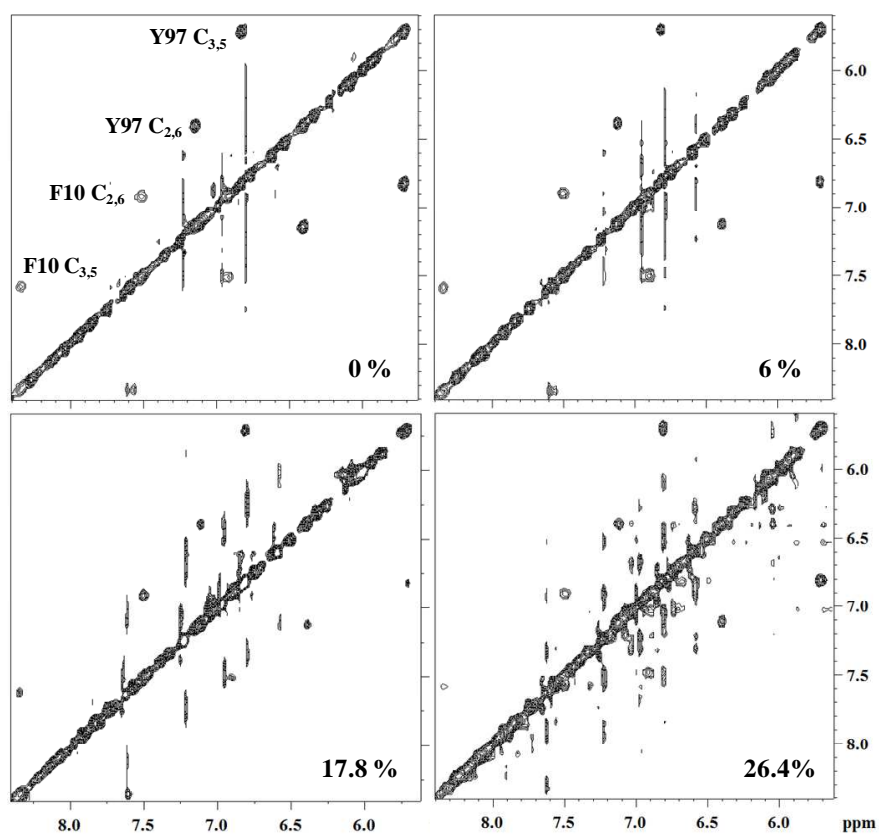

Figure S1. Region of the EXSY spectrum $\left(\tau_{\mathrm{m}}=37.5 \mathrm{~ms}\right)$ showing the cross peaks analyzed. Actual temperatures measured during experiments were $23.8,23.5,23.7$, and $23.9{ }^{\circ} \mathrm{C}$ for samples containing $0,6,17.8$, and $26.4 \%$ glycerol, respectively.

Rate coefficient for ring-flip was obtained $b y^{2,3}$

$\ln (-2 \Gamma+1)=-2 k_{\text {flip }} \tau_{m}$

where, $\Gamma=V_{\mathrm{c}} /\left(V_{\mathrm{c}}+V_{\mathrm{d}}\right)$, and $V_{\mathrm{c}}$ and $V_{\mathrm{d}}$ are cross- and diagonal peak volumes, respectively. Figure $\mathrm{S} 2$ provides an example.

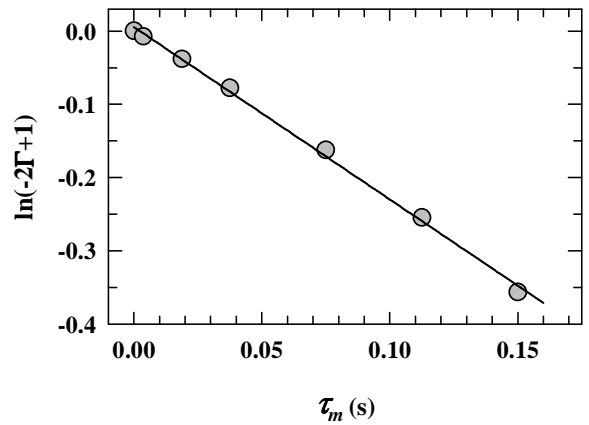

Figure S2. Data for $Y 97 \mathrm{C}_{3,5}$ flip rate in $26.4 \%$ glycerol, $50 \mathrm{mM}$ phosphate buffer, $\mathrm{pH} 7$. The value of $k_{\mathrm{flip}}\left(\mathrm{s}^{-1}\right)$ is the half of the slope of the line (1.34). 


\section{Determination of Adiabatic compressibility and Root Mean-Square Volume Fluctuation.}

Cytochrome $c$ solutions were prepared by varying glycerol percentage in the 0 to $60 \%$ range containing $50 \mu \mathrm{M}$ protein in $20 \mathrm{mM}$ phosphate buffer, $\mathrm{pH}$ 7.2. Solution density and sound velocity measurements were performed at $298 \mathrm{~K}$ with a precision of $\pm 1.5 \times 10^{-6} \mathrm{~g} \mathrm{~cm}^{-3}$ using a vibrating tube densitometer (DSA-5000M, Anton paar, Austria). The partial specific volume, $v^{\mathrm{o}}$, was calculated by

$v^{0}=\frac{1}{\rho_{\mathrm{o}}}-\frac{\rho-\rho_{\mathrm{o}}}{c \rho_{\mathrm{o}}}$

where $\rho$ and $\rho_{\mathrm{o}}$ are solution and solvent densities, respectively, and $c$ is the molar concentration of the protein. The partial specific adiabatic compressibility, $k_{\mathrm{s}}$, is obtained from

$k_{\mathrm{s}}=\beta_{\mathrm{o}}\left(2 v^{0}-2[u]-\frac{1}{\rho_{o}}\right)$

where $[u]=\left(u-u_{\mathrm{o}}\right) / u_{\mathrm{o}} c$ is relative specific sound velocity with $u$ and $u_{\mathrm{o}}$ being velocities in solution and solvent, respectively, and $\beta_{0}=1 /\left(\rho u_{2}\right)$ is coefficient of adiabatic compressibility of the solvent. The adiabatic compressibility of the solution, $\beta_{s}$, is given by

$\beta_{s}=\vartheta_{p} \beta_{s p}+\vartheta^{\prime} \beta_{s}^{\prime}+\left(1-\vartheta_{p}-\vartheta^{\prime}\right) \beta_{s}^{0}$

where, $\beta_{s p}, \beta_{s}^{\prime}$, and $\beta_{s}^{0}$ are compressibilities of protein, hydration water, and solvent, respectively, and $\vartheta_{p}$ and $\vartheta^{\prime}$ represent volume fractions of the protein and the hydration shell. The isothermal bulk compressibility, $\beta_{T}$, is approximated by $\beta_{S}{ }^{4}$. The variation of solution density $(\rho)$, and partial specific volume $\left(v^{o}\right)$ and partial molal adiabatic compressibility $\left(k_{\mathrm{s}}{ }^{\mathrm{m}}\right)$ of cytochrome $c$ at different \% glycerol are given in Figure S3. 

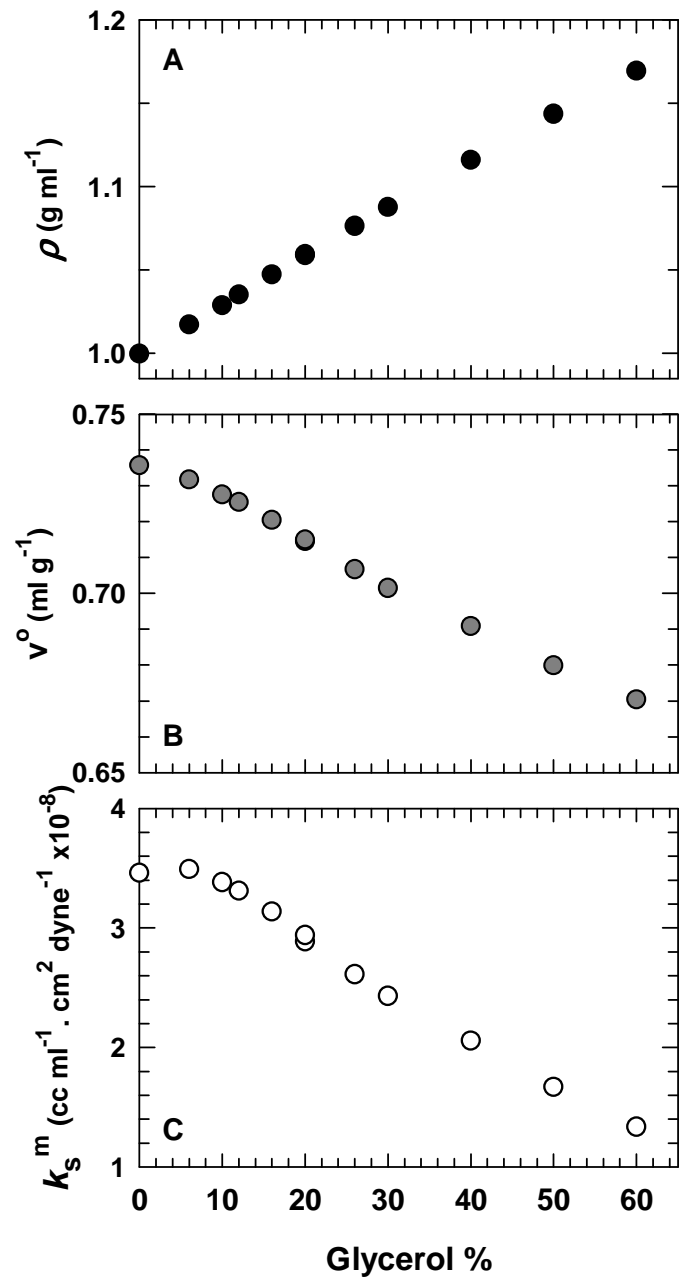

Figure S3. Glycerol dependence of (A) solution density, (B) partial specific volume, and (C) partial molal adiabatic compressibility of cytochrome $c$.

\section{References}

1. J. Fejzo, W. M Westler, S. Macura, J. L. Markley, J. Magn. Reson. 1991, 92, 20-29.

2. D. K. Rao, A. K. Bhuyan, J. Biomol. NMR 2007, 39, 187-196.

3. R. R. Ernst, G. Bodenhausen, A. Wokaun in Principles of Nuclear Magnetic Resonance in One and Two Dimensions, Clarendon Press, Oxford, 1988, pp. 490-538.

4. D. Eden, J. B. Matthew, J. J. Rosa, F. M. Richards, Proc. Natl. Acad. Sci. USA 1982, 79, 815-819. 